\title{
Pengaruh Customer Relationship Management dan Kepercayaan Merek Terhadap Loyalitas Pelanggan Telkomsel
}

\author{
Della Krissianty, Widayatmoko \\ della.915150046@stu.untar.ac.id,widayatmoko@untar.ac.id \\ Fakultas Ilmu Komunikasi Universitas Tarumanagara
}

\begin{abstract}
This study aims to determine Customer Relationship Management and activities that create brand trust so that customer loyalty arises. The theory used in this study is the theory of Public Relations, Customer Relations, Customer Relationship Management, brand trust and customer loyalty. This study uses quantitative research methods with survey methods. The research technique used is non probability with a purposive sampling approach with 100 people as respondents. Test requirements analysis using tests of validity, reliability, multicollinearity and heteroscedasticity. Data analysis using multiple correlation coefficients, coefficient of determination, multiple linear regression analysis, $t$ test and $F$ test. The results of the multiple correlation coefficient test are 0.580 which means having a relationship between medium variables, while the coefficient of determination results in $33.6 \%$ Telkomsel customer loyalty influenced by Customer Relationship Management and brand trust. The results of the t-test of the two variables are known that Ha is accepted, meaning that Customer Relationship Management activities and brand trust partially influence the loyalty of Telkomsel customers. Based on the $F$ test results it is known that $F$ table (3.09) $<F$ count $(24,538)$ then Ha is accepted, meaning that the variable Customer Relationship Management and brand trust have an effect on the loyalty of Telkomsel customers.
\end{abstract}

Keywords: Customer Relationship Management, Brand Trust and Customer Loyalty

Abstrak

Penelitian ini bertujuan untuk mengetahui Customer Relationship Management dan kegiatan yang menciptakan kepercayaan merek sehingga munculnya loyalitas pelanggan. Teori yang digunakan adalah teori Public Relations, Customer Relations, Customer Relationship Management, kepercayaan merek dan loyalitas pelanggan. Penelitian ini menggunakan metode penelitian kuantitatif dengan metode survey. Teknik sampling adalah non probability dengan pendekatan purposive sampling, responden sebanyak 100 orang. Uji persyaratan analisis menggunakan uji validitas, reliabilitas, multikolinearitas dan heteroskedastisitas. Analisis data menggunakan koefisien korelasi berganda, koefisien determinasi, analisis regresi linier berganda, uji t dan uji $\mathrm{F}$. Hasil dari uji koefisien korelasi berganda sebesar 0,580 artinya memiliki hubungan antar variabel sedang, sedangkan pada koefisien determinasi didapatkan hasil sebesar 33,6\% loyalitas pelanggan Telkomsel dipengaruhi oleh Customer Relationship Management dan kepercayaan merek. Hasil uji t kedua variabel diketahui bahwa Ha diterima, artinya kegiatan Customer Relationship Management dan kepercayaan merek secara parsial berpengaruh terhadap loyalitas pelanggan Telkomsel. Berdasarkan hasil uji $\mathrm{F}$ diketahui $\mathrm{F}$ tabel $(3,09)<\mathrm{F}$ hitung $(24,538)$ maka Ha diterima, artinya variabel Customer Relationship Management dan kepercayaan merek secara bersama-sama berpengaruh terhadap loyalitas pelanggan Telkomsel.

Kata Kunci: Customer Relationship Management, Kepercayaan Merek dan Loyalitas Pelanggan 


\section{Pendahuluan}

Manusia memiliki keinginan dan kebutuhan yang harus dipenuhi, oleh karena itu keinginan dan kebutuhannya dapat dipenuhi dengan melakukan konsumsi barang dan jasa. Hal ini menyebabkan perusahaan perdagangan semakin dituntut untuk memperhatikan keinginan konsumen serta berusaha memenuhi harapan konsumen akan pelayanan yang berkualitas dibandingkan pesaing. Perusahaan harus dapat membuat pelanggan merasa puas sehingga pelanggan dapat dipertahankan dan perusahaan dapat terus mempertahankan posisinya di pasar perdagangan.

Masyarakat khususnya penduduk kota Jakarta kebanyakan memiliki telepon pribadi yang menjadi bagian penting untuk melakukan aktivitasnya dengan maksimal, karena hal tersebut perusahaan telekomunikasi gencar dalam menjual produknya seperti kartu simcard, pulsa serta paket data (internet) yang digunakan masyarakat untuk berinteraksi melalui telepon serta menggunakan internet untuk mencukupi kebutuhan informasi.

Semakin banyak perusahaan telekomunikasi yang ada semakin banyak juga persaingan yang harus dihadapi. Akibat tingkat persaingan yang ketat, perusahaan akan berusaha untuk menarik pelanggan baru bahkan akan lebih memfokuskan dalam mempertahankan pelanggan yang sudah ada. Pelanggan merupakan kunci utama dari kesuksesan sebuah perusahaan. Keberlangsungan hidup perusahaan bergantung pada pelanggan yang membeli barang maupun jasa yang ditawarkan perusahaan dan melakukan pembelian ulang. Hal tersebut dinamakan pelanggan yang loyal. Perusahaan akan melakukan segala upaya untuk terus dapat mempertahankan pelanggannya agar tetap loyal.

Salah satu cara yang dapat dilakukan perusahaan dalam mempertahankan loyalitas pelanggannya adalah dengan menerapkan Customer Relations. Menurut Oesman (dalam Brown, 2010:38) Customer Relations adalah suatu proses kegiatan dalam mendapatkan dan mempertahankan serta menghasilkan nilai kepada pelanggan sehingga terbentuknya loyalitas pelanggan. Melalui kegiatan Customer Relationship Management berarti perusahaan memiliki perhatian kepada pelanggannya, pelanggan akan merasa menjadi bagian penting di perusahaan tersebut.

Tidak hanya Customer Relations yang dapat mempengaruhi loyalitas pelanggan. Namun juga kepercayaan konsumen terhadap merek yang memegang peran penting dalam terciptanya loyalitas konsumen. Menurut Ferrinadewi (2008:150) kepercayaan pelanggan dapat dibentuk dan diperoleh jika perusahaan dapat membentuk hubungan yang baik dan positif kepada pelanggan. Hubungan positif yang dibentuk perusahaan harus dibangun selama jangka waktu yang panjang, namun harus dilakukan secara konsisten dan persisten. Untuk dapat menciptakan loyalitas, perusahaan harus dapat menciptakan kepercayaan pelanggan terhadap suatu merek, karena loyalitas pelanggan terhadap merek tidak dapat diuji tanpa adanya kepercayaan pelanggan terhadap merek.

Menurut Griffin dalam Hurriyati (2010) loyalitas mengarah kepada bila pelanggan secara konsisten melakukan pembelian secara terus menerus maupun berulang terhadap barang atau jasa yang ditawarkan oleh perusahaan. Pelanggan yang loyal akan dengan senang hati mengungkapkan hal-hal yang positif dan memberikan rekomendasi mengenai perusahaan kepada orang lain. Loyalitas pelanggan merupakan sesuatu hasil yang telah dicapai perusahaan untuk terus dapat berdiri di persaingan yang ketat ini sehingga lebih baik mempertahankan pelanggan 
lama yang melakukan pembelian berulang serta merekomendasikan kepada orang lain dibandingkan mencari pelanggan baru.

Telkomsel merupakan salah satu perusahaan telekomunikasi terbesar di Indonesia yang telah berdiri selama 22 tahun. Telkomsel menawarkan berbagai produk yang digunakan masyarakat Indonesia terutama penduduk kota Jakarta. Dalam waktu yang tidak singkat tersebut, Telkomsel telah memiliki pelanggan yang tidak sedikit. Ditambah dengan munculnya beberapa perusahaan telekomunikasi yang membuat persaingan semakin ketat. Sehingga setiap perusahaan telekomunikasi berusaha untuk melakukan upaya untuk mempertahankan pelanggannya.

Customer Relationhip Management dan kepercayaan merek yang diberikan perusahaan akan menjadi tonggak utama untuk memiliki hubungan yang baik dengan pelanggan sehingga dapat memahami kebutuhan dan harapan pelanggannya. Berdasarkan uraian latar belakang diatas, peneliti menyadari bahwa kegiatan Customer Relationship Management dan kepercayaan merek dapat mempengaruhi loyalitas pelanggan pada pelanggan Telkomsel. Dalam hal ini, peneliti memilih kegiatan Customer Relationship Management dan kepercayaan merek karena berdasarkan pengalaman peneliti yang juga merupakan konsumen atau pelanggan Telkomsel, peneliti merasa dipermudah dalam melakukan pembelian produk Telkomsel seperti pulsa maupun paket data (internet) dan peneliti memiliki kepercayaan terhadap Telkomsel akan produknya yang juga merupakan perusahaan operator telekomunikasi seluler terbesar di Indonesia. Oleh karena itu penulis tertarik untuk mengangkat judul penelitian "Pengaruh Customer Relationship Management Dan Kepercayaan Merek Terhadap Loyalitas Pelanggan Telkomsel"

Berdasarkan latar belakang tersebut, peneliti dapat merumuskan masalah yaitu apakah tingkat pengaruh Customer Relationship Management terhadap loyalitas pelanggan Telkomsel, apakah tingkat pengaruh kepercayaan merek terhadap loyalitas pelanggan Telkomsel dan apakah tingkat pengaruh Customer Relationship Management dan kepercayaan merek terhadap loyalitas pelanggan Telkomsel. Tujuan dari penelitian ini untuk mengetahui pengaruh Customer Relationship Management terhadap loyalitas pelanggan Telkomsel, untuk mengetahui pengaruh pengaruh kepercayaan merek terhadap loyalitas pelanggan Telkomsel dan untuk mengetahui pengaruh Customer Relationship Management dan kepercayaan merek terhadap loyalitas pelanggan Telkomsel.

\section{Metode Penelitian}

Pendekatan penelitian yang digunakan dalam penelitian ini adalah pendekatan penelitian kuantitatif. Pendekatan kuantitatif Kasiram (2008: 149) adalah suatu proses yang dilakukan dalam penelitian yang menggunakan data berupa angka sebagai data yang dapat membantu menganalisis sesuatu yang ingin diketahui. Dalam penelitian ini, peneliti memilih pendekatan penelitian kuantitatif dengan metode survey. Menurut Sugiyono (2013:11) metode survey merupakan metode yang dilakukan dengan penyebaran kuesioner atau angket sebagai alat penelitian kepada populasi besar maupun kecil dengan meneliti sampel dari populasi tersebut.

Berdasarkan berita Warta Ekonomi yang diambil di media online (https://www.wartaekonomi.co.id/read173788/telkomsel-catatkan-1963-juta-

pelanggan.html), pelanggan Telkomsel tercatat sebanyak 196,3 juta pelanggan di akhir tahun 2017. Dalam penelitian ini, peneliti menetapkan jumlah sampel sebanyak 100 responden, dengan kriteria sampel yang sesuai dengan penelitian peneliti. 
Teknik penentuan sampel yang digunakan pada penelitian ini didasarkan pada metode non probability sampling dengan menggunakan pendekatan purposive sampling. Data dikumpulkan dengan penyebaran kuesioner dengan menggunakan skala Likert. Data primer dalam penelitian ini diperoleh melalui penyebaran kuesioner. Sedangkan data sekunder didapat melalui studi kepustakaan dan internet. Untuk mengetahui keabsahan data dalam penelitian ini, penulis menggunakan uji validitas, uji reliabilitas, uji multikolinearitas dan uji heteroskedastisitas. Sedangkan untuk pengolahan data dalam penelitian ini, penulis menggunakan uji koefisien korelasi berganda, uji koefisien determinasi, uji regresi linear berganda, uji t dan uji F.

Hipotesis dalam penelitian ini adalah sebagai berikut:

Ha $\left(\mathrm{X}_{1} \mathrm{y}\right)=0$ : terdapat pengaruh Customer Relations terhadap loyalitas pelanggan Telkomsel.

Ho $\left(\mathrm{X}_{1} \mathrm{y}\right) \neq 0$ : tidak terdapat pengaruh Customer Relations terhadap loyalitas pelanggan Telkomsel.

Ha $\left(\mathrm{X}_{2} \mathrm{y}\right)=0$ : terdapat pengaruh kepercayaan merek terhadap loyalitas pelanggan Telkomsel.

Ho $\left(\mathrm{X}_{2} \mathrm{y}\right) \neq 0$ : tidak terdapat pengaruh kepercayaan merek terhadap loyalitas pelanggan Telkomsel.

Ha $\left(\mathrm{X}_{1} \mathrm{X}_{2} \mathrm{y}\right)=0$ : terdapat pengaruh Customer Relations dan kepercayaan merek terhadap loyalitas pelanggan Telkomsel.

Ho $\left(\mathrm{X}_{1} \mathrm{X}_{2} \mathrm{y}\right) \neq 0$ : tidak terdapat pengaruh Customer Relations dan kepercayaan merek terhadap loyalitas pelanggan Telkomsel.

\section{Hasil Temuan dan Diskusi}

Penulis menyebarkan kuesioner kepada 100 responden. Dari 100 responden, mayoritas responden adalah perempuan. Dari segi usia, mayoritas responden berusia 17-25 tahun. Dengan mayoritas domisili Jakarta Barat dan mayoritas berstatus mahasiswa/pelajar.

Dari data 100 responden, penulis melakukan uji validitas dan uji reliabilitas untuk menguji 16 pernyataan yang terdapat pada kuesioner.

\begin{tabular}{|c|c|c|c|c|}
\hline \multicolumn{2}{|c|}{ No. Soal } & R Hitung & R Tabel & Keterangan \\
\hline \multirow{5}{*}{$\mathrm{X} 1$} & $\mathrm{P} 1$ & 0,756 & 0,2 & Valid \\
\hline & $\mathrm{P} 2$ & 0,677 & 0,2 & Valid \\
\hline & P3 & 0,697 & 0,2 & Valid \\
\hline & $\mathrm{P} 4$ & 0,613 & 0,2 & Valid \\
\hline & P5 & 0,602 & 0,2 & Valid \\
\hline \multirow{3}{*}{$\mathrm{X} 2$} & P6 & 0,819 & 0,2 & Valid \\
\hline & P7 & 0,804 & 0,2 & Valid \\
\hline & P8 & 0,764 & 0,2 & Valid \\
\hline \multirow{7}{*}{$\mathrm{Y}$} & P9 & 0,586 & 0,2 & Valid \\
\hline & $\mathrm{P} 10$ & 0,360 & 0,2 & Valid \\
\hline & $\mathrm{P} 11$ & 0,550 & 0,2 & Valid \\
\hline & $\mathrm{P} 12$ & 0,529 & 0,2 & Valid \\
\hline & $\mathrm{P} 13$ & 0,671 & 0,2 & Valid \\
\hline & P14 & 0,787 & 0,2 & Valid \\
\hline & P15 & 0,659 & 0,2 & Valid \\
\hline
\end{tabular}


Della Krissianty, Widayatmoko: Pengaruh Customer Relationship Management dan Kepercayaan Merek Terhadap Loyalitas Pelanggan Telkomsel

\begin{tabular}{llll} 
P16 & 0,494 & 0,2 & Valid \\
\hline
\end{tabular}

\section{Uji Reliabilitas X1}

Setelah diuji menggunakan SPSS, penulis mendapatkan hasil 0,766 untuk pernyataan X1 (Customer Relationship Management). Pernyataan tersebut dinyatakan reliabel karena $\mathrm{r}$ hitung $>\mathrm{r}$ tabel yaitu $0,766>0,70$.

Uji Reliabilitas X2

Setelah diuji menggunakan SPSS, penulis mendapatkan hasil 0,825 untuk pernyataan X1 (Kepercayaan Merek). Pernyataan tersebut dinyatakan reliabel karena $\mathrm{r}$ hitung $>\mathrm{r}$ tabel yaitu $0,825>0,70$.

Uji Reliabilitas Y

Setelah diuji menggunakan SPSS, penulis mendapatkan hasil 0,738 untuk pernyataan X1 (Loyalitas Pelanggan). Pernyataan tersebut dinyatakan reliabel karena r hitung $>\mathrm{r}$ tabel yaitu $0,738>0,70$.

Uji Multikolinearitas

Setelah diuji menggunakan SPSS, penulis mendapatkan hasil bahwa tingkat tolerance sebesar 0,628 yang berarti lebih besar dari 0,10 yang menunjukkan tidak multikolinearitas dan VIF sebesar 1,592 yang berarti lebih kecil dari 10 menunjukkan tidak multikolinearitas.

Uji Heteroskedastisitas

Setelah diuji menggunakan SPSS, penulis mendapatkan hasil bahwa menunjukkan signifikansi dari X1 (Customer Relationship Management) sebesar 0,732 dan X2 (Kepercayaan Merek) sebesar 0,177 yang berarti lebih besar dari 0,05 yang menunjukkan tidak terjadi heteroskedastisitas.

Teknik Keabsahan Data:

Uji koefisien korelasi berganda

Gambar 1. Koefisien Korelasi Berganda

\begin{tabular}{|l|l|r|r|r|}
\hline Model & R & R Square & $\begin{array}{c}\text { Adjusted R } \\
\text { Square }\end{array}$ & $\begin{array}{c}\text { Std. Error of } \\
\text { the Estimate }\end{array}$ \\
\hline 1 & $.580^{\mathrm{a}}$ & .336 & .322 & 4.11434 \\
\hline
\end{tabular}

Sumber: SPSS

Setelah diuji menggunakan SPSS, penulis mendapatkan hasil bahwa koefisien korelasi (r) dari variabel X dan Y dalam penelitian ini sebesar 0,580. Apabila nilai $r$ sebesar 0,580 menunjukkan hubungan antara Customer Relationship Management (X1), kepercayaan merek (X2) dan loyalitas pelanggan (Y) adalah sedang. Sugiyono, (2017:231).

Koefisien determinasi: Setelah diuji menggunakan SPSS, penulis mendapatkan hasil nilai koefisien determinasi dengan melihat angka yang ada pada $\mathrm{R}$ square. Hasil dari $\mathrm{R}$ square adalah 0,336 sama dengan 33, 6\% yang artinya variabel $\mathrm{X}$ dapat menjelaskan variabel Y sebesar 33,6\% dan sisanya 66,4\% dipengaruhi oleh variable lain. 
Analisis Regresi Linier Berganda:

Gambar 2. Analisis Regresi Linier Berganda dan Uji t

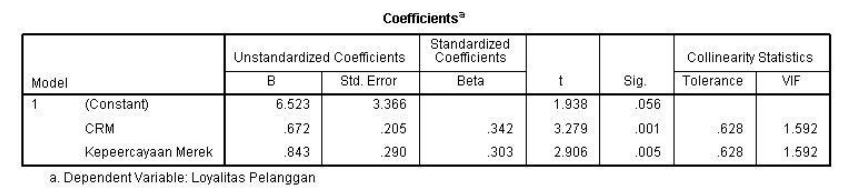

Sumber: SPSS

$$
\mathbf{Y}=\boldsymbol{\alpha}+\mathbf{b}_{1} \mathbf{X}_{1}+\mathbf{b}_{2} \mathbf{X}_{2}
$$

Setelah diuji menggunakan SPSS, penulis mendapatkan hasil nilai 0,672 merupakan koefisien regresi dari variabel Customer Relationship Management yang menunjukan bahwa setiap ada penambahan 1 nilai atau angka untuk variabel Customer Relationship Management akan terdapat kenaikan loyalitas pelanggan Telkomsel sebesar 0,672. Hal ini menunjukkan semakin besar nilai variabel X maka akan semakin mempengaruhi kenaikan nilai Y. Nilai 0,843 merupakan koefisien regresi dari variabel kepercayaan merek yang menunjukan bahwa setiap ada penambahan 1 nilai atau angka untuk variabel kepercayaan merek akan terdapat kenaikan loyalitas pelanggan Telkomsel sebesar 0,843. Hal ini menunjukkan semakin besar nilai variabel X maka akan semakin mempengaruhi kenaikan nilai Y. $\underline{\text { Uji t }}$

Setelah diuji menggunakan SPSS, penulis mendapatkan hasil uji t terhadap X1 bahwa nilai sig $<\alpha$ yaitu $0,001<0,05$ maka Ha diterima, maka Customer Relationship Management berpengaruh signifikan terhadap loyalitas pelanggan Telkomsel. Untuk hasil uji t terhadap X2 bahwa nilai sig < a yaitu 0,005 $<0,05$ maka Ha diterima, maka kepercayaan merek berpengaruh signifikan terhadap loyalitas pelanggan Telkomsel.

$\underline{\text { Uji F }}$

Gambar 3. Hasil Uji F

\begin{tabular}{|c|c|c|c|c|c|c|}
\hline \multicolumn{7}{|c|}{ ANOVA $^{\mathrm{b}}$} \\
\hline \multicolumn{2}{|c|}{ Model } & $\begin{array}{c}\text { Sum of } \\
\text { Squares }\end{array}$ & df & Mean Square & $\mathrm{F}$ & Sig. \\
\hline 1 & Regression & 830.754 & 2 & 415.377 & 24.538 & $.000^{a}$ \\
\hline & Residual & 1641.996 & 97 & 16.928 & & \\
\hline & Total & 2472.750 & 99 & & & \\
\hline
\end{tabular}

Sumber: SPSS

Setelah diuji menggunakan SPSS, penulis mendapatkan nilai $F_{\text {tabel }}$ adalah 3,09 dan nilai $F_{\text {hitung }}$ adalah 24,538 maka $F_{\text {tabel }}<F_{\text {hitung }}$ yaitu $24,538<3,09$, serta nilai sig $<0,05$ yaitu $0,000<0,05$. Hal ini dapat dikatakan hasil uji $\mathrm{F}$ adalah Ho ditolak dan $\mathrm{Ha}$ diterima, artinya variabel $\mathrm{X}_{1}$ dan variabel $\mathrm{X}_{2}$ secara bersama-sama mempengaruhi variabel $\mathrm{Y}$, maka terdapat pengaruh Customer Relationship Management dan kepercayaan merek terhadap loyalitas pelanggan Telkomsel. 
Della Krissianty, Widayatmoko: Pengaruh Customer Relationship Management dan Kepercayaan Merek Terhadap Loyalitas Pelanggan Telkomsel

Berdasarkan nilai rata rata untuk variabel X1 (Customer Relationship Management), dimensi tertinggi ada pada dimensi proses yang paling mempengaruhi loyalitas pelanggan Telkomsel. Untuk nilai rata-rata variabel X2 (kepercayaan merek), dimensi tertinggi ada pada dimensi demonstrate concern yang paling berpengaruh terhadap loyalitas pelanggan Telkomsel.

\section{Simpulan}

Membentuk dan mengembangkan hubungan yang baik antara penjual dengan pembeli merupakan adalah konsep dari Customer Relationship Management menurut Boone dan Kulrtz (2008:7). Tidak hanya kegiatan Customer Relationship Management, namun juga merek yang dapat memberikan kepercayaan kepada pelanggan dapat mempertahankan pelanggan.

Pada Customer Relationship Management terdapat empat dimensi yaitu data dan informasi, dimensi proses, dimensi teknologi dan dimensi sumber daya manusia menurut Kincaid (dikutip dari Francis Buttle, 2008). Dimensi data dan informasi yang mempengaruhi loyalitas pelanggan karena pelanggan merasa terpenuhi kebutuhan informasi yang dibutuhkan. Dari informasi mengenai harga simcard, pulsa dan paket internet. Seperti kuota internet yang akan didapat dengan harga sekian dan masa tenggangnya juga. Selain itu di dimensi teknologi, pelanggan juga dapat mengakses website yang disediakan Telkomsel dari tentang Telkomsel berdiri, visi dan misi hingga dapat melakukan pembelian dan juga aplikasi "My Telkomsel" yang dapat diunduh dan diakses oleh pelanggan untuk melakukan pembelian. Pada dimensi sumber daya manusia juga pelanggan diberikan kenyamanan dan kemudahan ketika melakukan pembelian secara langsung ke customer service yang dapat melayaninya dengan handal.

Dimensi proses merupakan dimensi tertinggi sebesar 422 yang paling mempengaruhi loyalitas pelanggan karena kebutuhan pelanggan dalam membeli produk Telkomsel maupun adanya keluhan dapat ditangani di fasilitas yang disediakan oleh Telkomsel yaitu graPARI. Hal ini tentunya memberikan pelanggan kemudahan dan kenyamanan sehingga pelangganpun akan loyal terhadap Telkomsel.

Dalam variabel X2 yaitu kepercayaan merek terdapat tiga dimensi yaitu achieving result, acting with integrity dan demonstrate concern menurut Ferrinadewi (2008:152). Dimensi achieving result juga mempengaruhi loyalitas pelanggan, karena pelanggan merasa misi yang disampaikan Telkomsel bahwa Telkomsel akan memberikan pelayanan yang melebihi ekspetasi pengguna dengan memenuhi harapan konsumen dalam kecepatan dan kemudahan dalam melakukan pembelian. Dalam dimensi acting with integrity, Telkomsel telah memenuhi ekspetasi harapan pelanggan dengan menunjukkan ketulusan dalam melayani pelanggan.

Dimensi demonstrate concern yang paling tinggi dengan nilai rata-rata sebesar 424 dalam mempengaruhi loyalitas pelanggan. Pelanggan merasa percaya kepada Telkomsel karena memiliki karyawan atau customer service yang dapat merasakan keluhan pelanggan serta dapat memberikan solusi yang tepat bagi masalah tersebut, sehingga pelanggan akan mudah dan nyaman bila ada keluhan maupun permasalahan karena dapat ditangani baik oleh customer service. 


\section{Ucapan Terima Kasih}

Penulis mengucapkan terima kasih kepada Bapak Drs. Widayatmoko, M.M.,M.I.Kom sebagai Dosen Pembimbing yang telah meluangkan waktunya untuk membimbing penulis serta Orangtua, responden dan sahabat penulis yang telah memberikan dukungan kepada penulis.

\section{Daftar Pustaka}

Boone, Louise.E \& Kurtz. (2008). Contemporary marketing. $11^{\text {th }}$ Edition. Thompson South Western: Cadotte. E.R

Ferrinadewi, Erna. (2008). Merek dan Psikologi Konsumen. Cetakan Pertama. Yogyakarta: Graha Ilmu

Hurriyati, Ratih. (2010). Bauran Pemasaran dan Loyalitas Konsumen. Bandung: Alfabetha.

Kasiram. (2008). Metodologi Penelitian Kuantitatif-Kualitatif. Malang: UIN Malang Press.

Kincaid, Judith W. (2008). Customer Relationship Management. Getting it right!. Prentice-Hall PTR, New Jersey

Oesman, Yevis Marty (2010). Sukses Mengelola Marketing Mix, CRM, Customer Value, Dan Customer Dependency, Bandung: Alfabeya

Sugiyono. (2013). Metode Penelitian Kuantitatif Kualitatif dan R\&D. Bandung: Alfabeta.

Rodiques, Rahanatha. (2018). Peran Brand Trust Memediasi Hubungan Brand Image Dengan Brand Loyalty (Studi Pada Konsumen Iphone Di Kota Denpasar). Jurnal Manajemen 7(3) 1310-1338

Bambang Ismoyo. (2018). 15 Maret 2018. Telkomsel catatkan 196,3 juta pelanggan. https://www.wartaekonomi.co.id/read173788/telkomsel-catatkan-1963-jutapelanggan.html, diunduh pada tanggal 30 oktober 2018 